\title{
LA ADMINISTRACIÓN ELECTRÓNICA EN ESPAÑA
}

Álvaro Sánchez Bravo ${ }^{1}$

\section{RESUMEN}

La administración electrónica supone el nuevo reto para la correcta implementación de la sociedad de la información y las comunicaciones en la relaciones de la Administración con los ciudadanos. España ha asumido ese desafío con entusiasmo, pero, al igual que sucede en la mayor parte de los socios comunitarios europeos, debe hacer frente a unos retos inaplazables, como la inclusión digital, la seguridad y privacidad de las comunicaciones y la lealtad y transparencia de sus actuaciones en los nuevos entornos digitales.

Palabras clave: Administración electrónica. Ciudadanos. España. Inclusión digital.

\section{EL PAPEL DE LA ADMINISTRACIÓN PÚBLICA EN LA SOCIEDAD DE LA INFORMACIÓN Y DE LA COMUNICACIÓN}

Numerosas son las reflexiones que, desde el promediar de la década de los setenta, se han ocupado de eso que se ha dado en denominar tecnologías de la información y de la comunicación (TIC), y sobre lo que hoy se conoce como "sociedad de la información".

Internet se ha consolidado como el símbolo emblemático de esa nueva realidad; como una de las piezas fundamentales de ese engranaje de la infraestructura mundial de la información².

El aumento exponencial del número de ordenadores, el desarrollo de sus capacidades operativas, la reducción del coste de los equipos, su penetración creciente en los hogares, las empresas y la administración, junto a la expansión de Internet, ha propiciado ese salto tecnológico que parece definir nuestra coitidianeidad. 
En este contexto la labor de la administración pública deviene capital. Las Administraciones públicas tienen ante sí el reto de adaptarse a las nuevas exigencias de mejora de productividad, de eficacia y de calidad en los servicios.

Para ello las nuevas tecnologías, y especialmente Internet, pueden ayudar a la consecución de tales objetivos. Pero no quedándose sólo en la introducción y en el uso de los nuevos recursos tecnológicos, sino asimilándolos, introduciendo los oportunos cambios jurídicos, institucionales, organizativos, e incluso redefiniendo su propio papel en los nuevos entornos tecnológicos.

Ello supone hacer frente, como premisa, a tres grandes desafíos:

1. Asimilar unas realidades sociales en constante transformación. El sector público puede convertirse en el principal motor de los cambios económicos y sociales, con el horizonte último de una mejora de la calidad de vida de los ciudadanos y de la cohesión social.

Los ámbitos de actuación del sector público, aumentan exponencialmente a medida que aumentan las necesidades de los ciudadanos, pero no sólo de manera cuantitativa, sino cualitativamente. Los ciudadanos no sólo quieren recibir prestaciones de la administración, sino que quieren saber como se adoptan las decisiones, e, incluso participar en algunas de ellas. Si la administración está llamada a ser la principal impulsora de los cambios, los ciudadanos quieren ser también protagonistas de esos cambios, y es a través de las nuevas tecnologías, como hoy se hace factible esas formulas de participación. Como ha señalado Erkki Liikanen, Comisario Europeo para la Sociedad de la Información: "El sector público, al igual que el resto de la economía, se enfrenta al desafío de reaccionar ante nuevos avances tecnológicos, en concreto en lo que respecta a la tecnología de la información y la comunicación. Internet ha hecho posible nuevas formas de participación en el diseño de políticas, tales como los grupos de opinión en línea, formados de manera muy rápida, o la exigencia a las autoridades públicas de que revisen su modo establecido de tomar decisiones". ${ }^{3}$ 
2. Dar respuesta a las nuevas expectativas. Los ciudadanos y las empresas demandan cada vez más, no sólo nuevos servicios, sino que estos se presten de manera más rápida y sin reiterar tramites engorrosos y reiterativos. Todo ello teniendo presente que las necesidades de los ciudadanos son diferentes, y que por lo tanto el objetivo estará en conseguir una atención personalizada al margen de la capacidad, cualificación o ubicación de aquéllos.

3. Ofrecer más con el mismo presupuesto. Las administraciones deben hacer frente a esas nuevas necesidades y exigencias en un escenario de control del gasto público y de contención presupuestaria. Así pues, con el mismo presupuesto deben ofrecerse más y mejores servicios. No olvidemos que debemos desenvolvernos en un entorno de estabilidad presupuestaria, pero sin renunciar a las prestaciones de los estados de bienestar como el nuestro.

Ante estos retos, la cuestión parece estar en la consecución de una nueva administración pública que encuentre en Internet y en las nuevas tecnologías el motor de su adaptación a las nuevas realidades: la administración electrónica o eadministración.

\section{LA ADMINISTRACIÓN ELECTRÓNICA}

La administración electrónica o e-administración es un concepto que surge de la implementación de las nuevas tecnologías con las técnicas clásicas de organización administrativa. Sin detenernos en la abundantísima literatura acerca de la definición precisa de que sea o que deba entenderse por administración electrónica, nosotros la conceptuaremos como la utilización de las tecnologías de la información y las comunicaciones en las administraciones públicas, asociada a cambios en la organización y nuevas aptitudes del personal. El objetivo es mejorar los servicios públicos, reforzar los procesos democráticos y apoyar a las políticas públicas ${ }^{4}$.

La administración electrónica se convertirá en un instrumento esencial para prestar unos servicios públicos más eficaces y de mejor calidad, reducir los tiempos de espera de los usuarios y mejorar la transparencia y la rendición de cuentas. 
Como ya indicamos anteriormente la administración electrónica o eadministración no se agota en la presencia de las administraciones públicas en Internet, ni siquiera en la prestación telemática de determinados servicios.

La situación actual registra un evidente progreso en su puesta en marcha. Tres son los ámbitos que deben considerarse:

-Para los ciudadanos, la administración electrónica supone ventajas en múltiples aspectos de su vida diaria. No sólo permite acceder a la información, sino que posibilita la realización de numerosas operaciones que evitandesplazamientos y mejora el tiempo de respuesta de la administración. Son numerosos los servicios de que disponen ya los ciudadanos, y que pueden clasificarse de acuerdo al siguiente cuadro.

\begin{tabular}{|c|c|c|c|}
\hline & $\begin{array}{l}\text { Servicios de } \\
\text { Información }\end{array}$ & $\begin{array}{l}\text { Servicios de } \\
\text { Comunicación }\end{array}$ & $\begin{array}{l}\text { Servicios de } \\
\text { Tramitación }\end{array}$ \\
\hline Vida Diaria & $\begin{array}{l}\text {-Información } \\
\text { sobre trabajo, } \\
\text { vivienda, } \\
\text { educación, salud, } \\
\text { cultura, } \\
\text { transporte, medio } \\
\text { ambiente, etc... }\end{array}$ & $\begin{array}{l}\text {-Foro de discusión } \\
\text { dedicado a las } \\
\text { preguntas de la vida } \\
\text { diaria. } \\
\text {-Boletines de empleo } \\
\text { y vivienda }\end{array}$ & $\begin{array}{l}\text {-Reserva y pago de } \\
\text { entradas. } \\
\text {-Inscripción en } \\
\text { cursos }\end{array}$ \\
\hline $\begin{array}{c}\text { Tele- } \\
\text { administració } \\
\mathrm{n}\end{array}$ & $\begin{array}{l}\text {-Directorio de } \\
\text { servicio Público. } \\
\text {-Guía para } \\
\text { procedimientos } \\
\text { administrativos } \\
\text { - Registros y } \\
\text { bases de datos } \\
\text { públicos. }\end{array}$ & $\begin{array}{l}\text { - Contactos por e- } \\
\text { mail con servidores } \\
\text { públicos }\end{array}$ & $\begin{array}{l}\text { - Tramitación } \\
\text { electrónica de } \\
\text { formularios }\end{array}$ \\
\hline
\end{tabular}




\begin{tabular}{|c|c|c|c|}
\hline $\begin{array}{l}\text { Participación } \\
\text { Política }\end{array}$ & $\begin{array}{l}\text {-leyes, } \\
\text { documentos } \\
\text { parlamentarios, } \\
\text { programas } \\
\text { políticos, } \\
\text { documentos de } \\
\text { consulta. } \\
\text { - Información } \\
\text { previa en las } \\
\text { tomas de } \\
\text { decisiones }\end{array}$ & $\begin{array}{l}\text { - Foro de discusión } \\
\text { dedicado a temas } \\
\text { políticos. } \\
\text { - Contacto por e-mail } \\
\text { con políticos. }\end{array}$ & $\begin{array}{l}\text {-Referendos. } \\
\text {-Elecciones. } \\
\text {-Consultas de } \\
\text { Opinión }\end{array}$ \\
\hline
\end{tabular}

Fuente: Sociedad de la Información en España 2003.Telefónica.

Pero además permite el establecimiento de una relación directa entre los administrados y los gestores públicos, haciendo las instituciones públicas más transparentes, responsables y abiertas al control democrático.

La proliferación de los foros virtuales, consultas en línea y los ensayos de voto electrónico permiten la comunicación directa de los ciudadanos con los responsables políticos, a los que pueden hacer llegar sus opiniones, quejas, sugerencias...

Asimismo, la consolidación de los servicios de ventanilla única constituye una formula adecuada para la prestación de servicios a los ciudadanos ${ }^{5}$.

- Para las empresas, la mejora de los servicios administrativos generan ganancias por cuanto ahorran tiempo y dinero en sus relaciones con la administración, y repercute en un aumento de la eficacia y la productividad. Hay que señalar que en este sector se ha avanzado notablemente más que en relación a los servicios ofertados a los ciudadanos.

- Para las administraciones públicas, el uso de Internet y de las nuevas tecnologías permite incrementar la coordinación entre los ámbitos nacional, autonómico y local. Especialmente importante, en nuestro modelo descentralizado.

Pese a los avances, la situación dista mucho de ser satisfactoria, pese a los avances. El Barómetro del CIS refleja como, en enero de 2004 , un $55^{\prime} 3 \%$ de los encuestados estaría muy interesado en consultar los servicios administrativos u 
obtener documentos a través del ordenador o teléfono móvil. No obstante, solo un 40 7\% (juntando los valores de muy probable y probable) creen que tales actividades podrán realizarlas personalmente. Todo ello teniendo en cuenta que el $59^{\prime} 2 \%$ declara no usar nunca un ordenador ${ }^{6}$. Se evidencia como un número considerable de ciudadanos estaría dispuesto a utilizar los servicios telemáticos en sus relaciones con la administración, pero falla en lo básico: la mayor parte no tiene acceso a Internet.

De manera que una cosa es disponer de la tecnología y otra que se esté dispuesto a usarla. Los ciudadanos no sólo deben usar determinada tecnología, sino que deben ser participes de los beneficios que la misma incorpora. La tecnología si no cuenta con la aceptación de los usuarios, no sirve para nada, queda en papel mojado. La "alfabetización digital" se revela pues como una premisa capital. Pero no sólo para facilitar sus relaciones con la administración, sino para la correcta comprensión de la realidad que nos ha tocado vivir, donde lo tecnológico parece ser el símbolo emblemático de nuestra cultura.

Para asumir estos cambios, necesario e indispensable es superar los obstáculos que frenan su implantación o avance. La conciencia sobre ambos aspectos nos hará caminar por la senda adecuada; el obviarlos nos hará perder un tiempo precioso, despilfarrar recursos y, en definitiva, perjudicar a los ciudadanos.

\section{OBSTACULOS Y BARRERAS PARA LA CORRECTA IMPLANTACIÓN DE LA ADMINISTRACIÓN ELECTRÓNICA}

El salto de la prestación de determinados servicios telemáticos, utilizando como soporte Internet, hasta la consecución de una disponibilidad generalizada y un uso "universal" de los servicios ofertados exigen que nos detengamos en la consideración de los principales obstáculos que en la hora presente dificultan esa transición. Sin animo de ser exhaustivos, tres son los aspectos más relevantes a considerar.

a) Acceso para todos. 
Sólo si todos los ciudadanos, en condiciones de igualdad, tienen posibilidad de acceder a los servicios públicos en línea, podrá cimentarse correctamente la administración electrónica.

Esto supondrá la posibilidad creciente de los individuos de participar plenamente en la vida social de la colectividad, evitando toda forma de exclusión, con todas las consideraciones políticas y jurídicas que ello implica ${ }^{7}$.

A ambos objetivos puede contribuir la sociedad de la información e Internet si partimos de la premisa de que es esencial que las personas, o los grupos en que se integran, no sean forzadas a ajustarse a las nuevas tecnologías, si no que sean las nuevas tecnologías las que se adapten a las necesidades de los hombres.

Cuestión capital resulta asimismo la consideración de los problemas que pueden plantearse para determinados colectivos desfavorecidos, tales como los pobres, enfermos, minusválidos, marginados... El riesgo de "fractura digital" vinculado a la desigualdad en el acceso a la tecnología no es demagogia; es una cuestión real. Esta situación puede ser especialmente difícil para el numero considerable de analfabetos que aún existen, para los inmigrantes que desconocen la lengua del país de acogida, y, en general, para aquellas personas que tengan cualquier problema de aprendizaje ${ }^{8}$.

Es por ello que los grupos que tengan un riesgo de exclusión sean especialmente integrados en la sociedad de la información, prestando una especial atención a sus concretas necesidades, pues las TIC, y especialmente Internet, pueden contribuir sustancialmente a la mejora de su calidad de vida.

La inclusión de todos en la sociedad tecnológica requerirá la apuesta por un acceso rápido y generalizado a Internet.

Por otra parte, es precisa que se consolide, y sea verdaderamente operativo, la migración desde las redes de banda estrecha a las redes de banda ancha que puedan soportar con fiabilidad y eficacia el evidente aumento del tráfico en la Red. De este modo, las estrategias nacionales de banda ancha tienen que tener como objetivo incrementar la cobertura en las zonas insuficientemente servidas y estimular la demanda ${ }^{9}$. 
Un reciente informe de la Comisión Europea pone de manifiesto como el número de particulares y empresas con acceso a Internet de alta velocidad experimentó un crecimiento del $80 \%$ en los doce meses anteriores a enero de 2004 . Con todo, los poderes públicos siguen teniendo un papel que desempeñar en los casos en los que los mercados no proporcionan las inversiones necesarias.

\section{b) Generar confianza en los usuarios.}

Un elemento capital en el desarrollo de la administración electrónica es el que el ciudadano confíe en lo que la moderna tecnología le aporta, en que se sienta cómodo y seguro. Que conozca que el sistema es fiable y no permite la intrusión de terceros.

Cuestiones como la protección de datos, la certificación digital y la seguridad de los sistemas informáticos son asuntos en los que las administraciones públicas no pueden permitirse ningún fallo. Los ciudadanos tienen que saber que, cuando, para que y durante que periodo sus datos van a ser usados, almacenados. En definitiva, que su derecho a la libertad informática está garantizado ${ }^{10}$.

Junto a ello el ciudadano debe tener la seguridad que la Administración comprobará con diligencia y rapidez su identidad, le proporcionará herramientas de autentificación electrónica (firma electrónica y certificados digitales), desarrollando aplicaciones para evitar intrusiones no deseadas o "robos de identidad"11.

Los sistemas electrónicos exigirán, igualmente, una infraestructura de comunicaciones segura, con unos equipos y programas seguros, que deberán responder a tres exigencias ineludibles: confidencialidad (impedir la divulgación no autorizada de los datos), integridad (impedir la modificación no autorizada de los datos) y disponibilidad (impedir la retención no autorizada de información o recursos) ${ }^{12}$.

En los últimos tiempos, las tensiones a escala internacional han supuesto un recrudecimiento de los ataques contra los sistemas de información y, de manera concreta, contra los sitios Internet. Ahora bien, recientes sucesos, como los desgraciados 11-S, y nuestro más reciente 11-M, así como determinados ataques 
informáticos, ponen de manifiesto la necesidad de garantizar la integridad, continuidad y fiabilidad de las redes y los servicios públicos. De todos es conocido como la Red presenta un alarmante déficit de seguridad y se ha convertido en instrumento, en numerosas ocasiones contundentemente eficaz, para la realización o aseguramiento de diversas actividades delictivas ${ }^{13}$.

Todo ello ha movido a numerosos Estados ${ }^{14}$ y organizaciones internacionales ${ }^{15}$ (especialmente del Consejo de Europa ${ }^{16} y$ de la Comisión Europea ${ }^{17}$ ) ha desarrollar propuestas legislativas y Convenios que prevengan y luchan contra esta amenaza, cuya extensión real se desconoce.

No obstante, esta preocupación se ha resuelto, casi generalizadamente, en una ampliación de las facultades investigadoras y represivas de las agencias policiales y de seguridad en las comunicaciones electrónicas ${ }^{18}$.

Se trata, por tanto, de conseguir un equilibrio entre el ejercicio de los derechos ciudadanos, y las necesarias medidas de seguridad y control en un mundo convulso como el que nos ha tocado vivir, donde la libertad y la seguridad juegan un difícil equilibrio.

\section{c) Interoperabilidad técnica.}

Junto a la problemática de naturaleza social, la cuestión técnica debe igualmente considerarse. La interoperabilidad hace referencia a los mecanismos que permiten la interconexión de los sistemas, de la información y de las distintas formas de trabajar.

La realidad es que aún los servicios administrativos están muy fragmentados, teniendo el ciudadano que peregrinar de unos sitios a otros en busca de respuesta a su peticiones. La solución por tanto vendrá del establecimiento de un punto unificado ("ventanilla única), que permita que todas las operaciones puedan realizarse de manera integrada, con independencia de los órganos administrativos que participen (que por otra parte, al ciudadano no le interesan). 
Pero para que eso sea una realidad es necesario que todas las fuentes de información, los documentos, los métodos de trabajo sean compatibles entre ellos y puedan ponerse en común, de manera ágil y eficaz.

Como ha señalado Erkki Liikanen: "la interoperabilidad no es solamente una cuestión técnica sobre como enlazar las redes; también tiene que ver con cuestiones organizativas como puede ser la coordinación de procesos que no solo abarcan límites intraorganizativos, sino que implican a organizaciones cuyos socios bien podrían tener diferentes organizaciones y modos internos de operar. El fracaso a la hora de introducir sistemas interoperativos de administración electrónica tendrá costes tanto económicos como sociales que incluyen: administraciones públicas estáticas impasibles que resultan caras de costear y son incapaces de aplicar las políticas de la manera más oportuna; incapacidad de desarrollar servicios de administración electrónica de valor añadido; altos costes, mayores cargas administrativas y desventajas competitivas para las empresas" ${ }^{19}$.

\section{LA NECESIDAD DE UN NUEVO MODELO DE ADMINISTRACIÓN PÚBLICA}

La situación de la administración electrónica y los obstáculos que ralentizan su total implantación, no deben desviarnos de otra cuestión capital: la necesidad de un nuevo modelo y diseño de las administraciones públicas. Las causas no son solamente exógenas, sino también endógenas.

Los tradicionales, y en muchas ocasiones engorrosos protocolos de actuación administrativa, se ven ahora modificados por el entorno tecnológico. Pero las nuevas tecnologías deben ser no sólo una herramienta, sino un catalizador que permita el cambio, tanto en la forma de relacionarse con los ciudadanos, como en la propia dinámica de actuación administrativa.

Como es obvio, la Administración debe orientarse a la satisfacción de las necesidades de los ciudadanos. Así pues, la organización del sector público debe centrarse en el usuario, de modo que esté al servicio de las personas. Y ello en una doble línea: por un lado, modificando sus procedimientos, haciéndolos más claros y sencillos; por otro, ampliando el número de servicios disponibles para comunicarse, 
incentivando el uso de las nuevas tecnologías, especialmente Internet. Se trata de pasar del "vuelva usted mañana" a "venga cuando quiera o pueda". Como ha señalado Bueno García: "En esta nueva Administración se sitúa a los ciudadanos y usuarios en un lugar central, y a los funcionarios y empleados públicos como verdaderos protagonistas del cambio. La calidad y la orientación al cliente han pasado a formar parte de los objetivos primordiales de la modernización administrativa. El ciudadano se ha convertido en el referente de toda actuación, lo que ha conllevado fenómenos de apertura que han llevado a la redefinición de los objetivos de las organizaciones públicas" ${ }^{20}$.

Pero para que ello sea posible es necesario asumir determinadas mutaciones.

\section{a) Cambios de organización}

La administración electrónica exigirá un rediseño de los procedimientos administrativos, tanto en su vertiente interna, como externa.

Desde el punto de vista interno, es necesario la informatización, la racionalización y la reingeniería de los procesos ${ }^{21}$. Y la eficacia se conseguirá cuando esa disponibilidad de información, y esa nueva forma de actuar se extienda a todos los órganos involucrados en la resolución de un procedimiento administrativo. Este salto hacia los procesos tecnológicos en la Administración pública requerirá una sinergia de esfuerzos de tal forma que el proceso de cambio se realice de manera unitaria, racionalizando y evitando el despilfarro.

Desde de el punto de vista externo, el objetivo debe ser la disponibilidad semper et ubique de los servicios ofertados al ciudadano (24 horas x 365 días) y desde cualquier punto que cuente con acceso a la Red. A este respecto la deslocalización permite que la administración gestione sus servicios sin necesidad de concentrar gran cantidad de personal y recursos en mastodónticas sedes físicas que centralicen los procesos administrativos.

Pero, como ha señalado el Informe sobre sociedad de la información en España 2003: "dentro de este esfuerzo cabe mencionar dos aspectos en los que es 
necesario avanzar:- la sofisticación de los servicios que depende fundamentalmente de la dificultad de poner en marcha las distintas fases del proceso administrativo... y - la unificación del punto de acceso... En la actualidad y debido a la estructura administrativa descentralizada existente en España, el debate debe centrarse en cuál es el punto de acceso más adecuado para acercarse al ciudadano"22.

\section{b) Cooperación interadministrativa}

Los cambios organizativos apuntados devienen inoperantes sino van acompañados de un proceso de cambio en todas las estructuras administrativas y en los distintos niveles administrativos territoriales.

El verdadero cambio se producirá cuando las adaptaciones a los nuevos marcos tecnológicos se realice de manera simultanea y coordinada entre las distintas administraciones. Somos conscientes de la dificultad del proceso, pero es la única solución operativa.

Ahora bien, los niveles de exigencia deberán ser asimétricos, porque la unificación, no puede devenir homogeneización, relegando a las administraciones periféricas a meros comparsas o brazos ejecutores de la política de la administración central.

El objetivo último de atención al ciudadano, requerirá que se establezcan modelos coordinados de descentralización administrativa, que ajustados al principio de subsidiariedad, permita que los servicios se presten con la máxima cercanía a los ciudadanos.

En esta línea ASTIC, ha postulado como cuestión prioritaria para la modernización de la administraciones públicas "la coordinación entre los distintos niveles de la administración y los diversos centros administrativos en cada una de ellas, en especial para hacer la administración menos compleja a los ojos de los ciudadanos que no tienen por qué ser expertos en "Competencias Administrativas", sino que deben poder acercarse a la oficina que más cómoda le resulte, donde deben ser atendidos desde una visión solidaria que internamente resuelva las 
cuestiones relativas a las competencias (que son de gran importancia para el conjunto de las administraciones pero no para los ciudadanos). Esto es cierto tanto en el mundo físico como en el virtual, los sitios de Internet tienen que estar diseñados para facilitar la vida del ciudadano y no para mostrar la gran complejidad de las Administraciones en su conjunto" ${ }^{23}$.

Hasta ahora los modelos administrativos autonómicos y locales han sido deudores del modelo estatal tradicional, pero el propio desarrollo autonómico y la creciente autonomía municipal hacen que sea preciso avanzar hacia nuevas formulas organizativas, donde se preste relevancia al propio valor añadido del servicio.

Otro problema, este de naturaleza técnica, es la necesaria estandarización de los mecanismos y protocolos de comunicación, para que los sistemas puedan comunicarse entre ellos de forma rápida y tener a acceso a la información disponible en cada uno de los organismos participantes.

\section{c) Formación del personal}

Los procesos tecnológicos, y su implantación en las administraciones públicas, no podrá llevarse a cabo sin el necesario concurso del personal de las administraciones públicas. Los cambios en el diseño organizativo de las administraciones tienen una inmediata repercusión en el personal que trabaja en ellas.

Debe diseñarse, por tanto, una adecuada estrategia de recursos como uno de los ejes de articulación. Igualmente, debe superarse el recelo a determinados cambios organizativos.

En sus prístinas aplicaciones, la tecnología fue vista como un enemigo que podría acabar con numerosos puestos de trabajo, al realizar de manera rápida gran cantidad de tareas, que antes estaban encomendadas a determinadas unidades. Incluso algunos auguraron la sustitución del hombre por la máquina. La realidad ha evidenciado como las nuevas tecnologías han propiciado la eliminación de 
determinadas tareas rutinarias, permitiendo al personal el desarrollo de tareas más creativas, liberados ya de la monotonía y del repetir siempre lo mismo.

Pero para que ello sea una realidad es necesario que se abra un proceso de comunicación con el personal que no sólo les haga ver, sino que los haga actores de las posibilidades vinculadas a los nuevos servicios prestados.

Ello nos lleva a una segunda consideración capital: la formación. Pero no una formación centrada única y exclusivamente en el manejo y conocimiento de las herramientas y las aplicaciones informáticas, sino en las implicaciones globales que su uso tendrán en la prestación del servicio y en las nuevas formas de trabajo.

\section{SITUACION ACTUAL DE LA ADMINISTRACIÓN ELECTRÓNICA EN ESPAÑA - MARCO NORMATIVO}

Si bien algunas iniciativas para el fomento de la sociedad de la información no ha obtenido el éxito deseado, España es puntera en algunos sectores claves (pago de impuestos a través de Internet $^{24}$, pago de cotizaciones laborales ${ }^{25}$ cumplimentación del censo ${ }^{26}$, certificación y firma electrónica ${ }^{27} \ldots$..).

Por otro lado, existen una serie de servicios que requieren un esfuerzo adicional, ya que se encuentran algo atrasados en cuanto a su implantación (licencias de obras, comunicación de cambio de domicilio, compras públicas por Internet y obtención de pasaporte y permiso de conducir).

Existen otros servicios en los que España ha avanzado considerablemente. Cabe destacar los servicios de subsidio de desempleo (50\% de accesibilidad), la ayuda familiar ( $50 \%$ ), las becas de estudio (50\%), el reembolso de gastos médicos (25\%), la matriculación universitaria (68 \%), la matriculación de vehículos (28,5\%), los permisos y licencias medioambientales (54\%), los servicios relacionados con la salud (vg. cita previa por Internet) (30\%) y el registro de nuevas sociedades $(75 \%)$, pero en los que no se ha obtenido la accesibilidad electrónica plena. 
Finalmente, existe una tercera categoría de servicios en los que España ha alcanzado ya el 100 por 100 de accesibilidad a través de Internet: pago de impuestos, denuncias ante la policía, servicios de bibliotecas públicas, presentación del impuesto de sociedades, envío de datos a oficinas estadísticas, presentación del IVA, las declaraciones de aduanas y los certificados de nacimiento y matrimonio ${ }^{28}$.

Los datos expuestos muestran como es necesario seguir avanzando en la implantación de la administración electrónica con la incorporación de nuevos servicios que sean accesibles y útiles para los ciudadanos.

Es ingente el número de portales en Internet de las Administraciones públicas, cifrados alrededor de los 2600 a finales de 2003. Decidida ha sido la apuesta de las distintas administraciones públicas por afianzar su presencia en la Red, pero eso no es todo. No basta con tener un portal en la Red, sino que a través de ese portal se puedan hacer cosas, se puedan prestar servicios a los ciudadanos.

En este sentido merece destacarse El Portal del Ciudadao (www.administración.es/portadas/index.html) que es el portal general en el que la Administración General del Estado informa con carácter general. Está dividia en tres ámbitos operativos (ciudadano, empresa y organización pública).

Para el ciudadano, su eficacia también reside en una serie de enlaces, donde de manera sencilla permite el acceso a todos los contenidos y servicios de interés para el ciudadano. Para las empresas permite el acceso a la Ventanilla Única Empresarial Virtual (www.vue.es) donde se ofrece información general sobre creación de empresas, trámites de proyectos empresariales y seguimiento de los mismos.

Igualmente relevantes es el hecho que a través del enlace Administración en Internet permita el acceso, bien por materias, bien por Comunidades Autónomas, a los servicios que ofertan cada una de las administraciones y su nivel de implantación (información, descarga de formularios y/o envío de formularios, y servicio on line). 
Junto a ello cabe reseñar el esfuerzo de las Comunidades Autónomas, por implantar en sus respectivos ámbitos territoriales servicios telemáticos de valor añadido y accesibles para los ciudadanos. Donde todavía debe procederse a un impulso mayor es en el ámbito de las Corporaciones Locales.

Desde el punto de vista normativo, los avances son también notorios. Frente a las reticencias de una cultura jurídica, en ocasiones anclada en el pasado, el derecho y sus instrumentos jurídicos pueden convertirse en instrumentos de gestión del cambio y de apoyo a la innovación en la cultura jurídica ${ }^{29}$.

Donde más se ha notado esa mutación ha sido en las relaciones con los administrados, especialmente en cuanto a la simplificación administrativa a través de unas adaptaciones normativas que tengan en cuenta las nuevas soluciones tecnológicas.

Ya la Ley 30/1992, de 26 de noviembre, de Régimen Jurídico de las Administraciones Públicas y del Procedimiento Administrativo Común, en su art. 45, insta a las Administraciones Públicas a que impulsen el empleo y aplicación de técnicas electrónicas y telemáticas para el desarrollo de sus actividades y el ejercicio de sus competencias ${ }^{30}$.

Esta promoción general se vio impulsada legislativamente con la reforma que incorporaba la Ley 24/2001, de medidas fiscales, administrativas y de orden social ${ }^{31}$, cuyo art. 68, modificaba dos artículos de la Ley 30/1992. El art. 38, para permitir la creación de registros telemáticos ${ }^{32}$; y el art. 59, para regular las notificaciones practicadas por medios telemáticos ${ }^{33}$.

Por su parte, el Real Decreto 263/1996, de 16 de febrero, por el que se regula la utilización de técnicas electrónicas, informáticas y telemáticas por la Administración del Estado, aborda el desarrollo del art. 45 de la Ley 30/1992, con la pretensión, como señala en la Exposición de Motivos, de "delimitar, en el ámbito de la Administración General del Estado, las garantías requisitos y supuestos de utilización de las técnicas electrónicas, informáticas y telemáticas". Este Real Decreto es muy relevante igualmente por que incorpora las garantías y derechos 
que los ciudadanos tienen frente a la administración cuando ésta utiliza medios tecnológicos ${ }^{34}$.

Por otro lado, en el Real Decreto 772/1999, de 7 de mayo, se regula la presentación de solicitudes, escritos y comunicaciones ante la Administración General del Estado, la expedición de copias de documentos y la devolución de originales y el régimen y funcionamiento de las oficinas de Registro ${ }^{35}$.

Para alcanzar los objetivos reseñados anteriormente, resultaba necesario regular el funcionamiento de los registros telemáticos, las notificaciones, certificados y transmisiones telemáticas. A ello va dirigido el Real Decreto 209/2003, de 21 de febrero, por el que se regulan los registros y las notificaciones telemáticas, así como la utilización de medios telemáticos para la sustitución de la aportación de certificados por los ciudadanos ${ }^{36}$.

Como señala su memoria justificativa, "resulta fundamental tener en cuenta las ventajas que desde el punto de vista de la gestión administrativa representa la presentación telemática de las solicitudes y demás documentación exigible. Ello permitirá agilizar los trámites administrativos y reducir los plazos de notificación y resolución".

Esta norma viene a dotar de consistencia jurídica a todas aquellas previsiones que habíamos visto promovían o impulsaban el uso de medios telemáticos en la Administración. Así constata en su propio articulado ( 3 artículos) dirigidos a modificar (completar) los Reales Decretos 263/1996 (se le añaden los nuevos Capítulos IV y V y dos nuevas Disposiciones Adicionales) y 772/1999 ( se le añade un nuevo Capítulo VI).

Tres son los ámbitos fundamentales objeto de regulación:

\section{Notificaciones telemáticas}

El sistema de notificaciones telemáticas, constituía una de las medidas incluidas en el Plan de Choque. El Real Decreto autoriza que los órganos 
administrativos y los organismos públicos habiliten sistemas de notificación utilizando medios telemáticos. Como señala su memoria justificativa: "Mediante las notificaciones telemáticas se introduce un nuevo instrumento de comunicación entre el ciudadano y la Administración que contribuirá a simplificar tanto estas relaciones como la actividad de la Administración. La reducción de las cargas y barreras burocráticas que la actividad administrativa impone se ha convertido en el correlato indispensable de las medidas de liberalización económica y fomento de la iniciativa privada y la libre competencia.

Una de las ideas subyacentes a este Real Decreto es el fomento de una nueva cultura administrativa en la que el papel, en la medida de lo posible, vaya siendo sustituido por los documentos telemáticos, con los ahorros tanto económicos como de espacio físico que ello implicará".

Para los interesados (ciudadanos y/o empresas), la notificación telemática será gratuita y voluntaria, debiendo manifestarse expresamente tal opción, bien indicando en su solicitud, escrito o comunicación la opción por la notificación telemática, bien aceptando la propuesta en este sentido del órgano u organismo público.

Pero para que ello sea posible el interesado deberá disponer de una dirección electrónica única ${ }^{37}$ habilitada al efecto, que deberá reunir tres características:

- Disponer de identificación de usuarios y claves de acceso para garantizar la exclusividad de uso.

- Disponer de mecanismos de autenticación de la identidad del usuario.

- Disponer de sistemas de cifrado que garanticen la confidencialidad de los datos.

El periodo de vigencia de la dirección electrónica única será indefinido, salvo en los casos previstos en la norma ${ }^{38}$, entre los que merece destacarse el transcurso de tres años sin que se utilice para la práctica de notificaciones. En tal supuesto, la propia administración inhabilitará la dirección, comunicándoselo al interesado. 
Respecto a su ámbito material, las notificación telemática solo será operativa para los procedimientos expresamente señalados ${ }^{39}$ por el interesado, quien queda vinculado a esta forma de notificación. No obstante se prevé una excepción cuando por causas técnicas justificadas el interesado, no la Administración, requiera que las notificaciones sucesivas se practiquen de manera ordinaria.

De esta forma, la dirección electrónica se convierte en el "domicilio electrónico" de los ciudadanos y empresas, en donde, de forma inmediata y personalizada, pueda acceder a sus notificaciones o documentos las 24 horas al día con total garantía de seguridad y confidencialidad de los participantes y la información gestionada.

Por otra parte, para garantizar la regularidad en la tramitación administrativa, el sistema de notificación deberá acreditar la fecha y hora en que se produzca la recepción de la notificación en la dirección electrónica del interesado, así como el acceso del mismo al contenido del mensaje de notificación. Igualmente deberá comunicar las incidencias técnicas que impidan el cumplimiento de las garantías anteriores.

Cuando exista constancia de la recepción de la notificación se dispone de 10 días naturales para su lectura. Si no se procediera a su lectura en ese plazo, ésta se consideraría rechazada y, aunque pueda acceder a su contenido, se generará un acuse automático de rechazo de dicha notificación ${ }^{40}$.

Los efectos jurídicos de las notificaciones telemáticas serán los mismos que los de las notificaciones tradicionales practicadas en soporte papel.

Este servicio entró en funcionamiento el 22 de octubre de 2003, mediante la firma de un convenio entre el Ministerio de Administraciones Públicas (responsable de su ejecución) y Correos (prestadora material del servicio). Al mismo se han adherido la Agencia Estatal de Administración Tributaria y la Tesorería General de la Seguridad Social ${ }^{41}$. 
De igual forma se prevé que mediante convenios con la Administración General del Estado, las Comunidades Autónomas y las administraciones locales podrán utilizar, en sus relaciones con los ciudadanos, el servicio de dirección electrónica única.

\section{Certificados telemáticos y transmisiones de datos}

Siempre que el interesado lo autorice o una norma legal lo disponga se sustituirán los certificados en soporte papel por certificados telemáticos o transmisiones de datos.

Los certificados telemáticos contendrán los datos objetos de certificación y la firma electrónica de la autoridad expendedora.

Dos son los supuestos en los que se expenderán certificados electrónicos:

- A solicitud del interesado, a quien se le enviará, y será éste el encargado de presentarlo ante quien se lo requiere.

- A solicitud el órgano requirente, bien a iniciativa del interesado, o del propio órgano requirente, pero siempre contando con el consentimiento expreso del interesado. En este caso se hará constar el trámite o procedimiento para el que se solicita el certificado y que se cuenta con el consentimiento del interesado. Éste habrá de constar en la solicitud de iniciación del procedimiento o en cualquier comunicación posterior.

En lo tocante a su eficacia jurídica, los efectos de la certificaciones telemáticas serán los mismos que los expedidos en soporte papel.

Respecto a las transmisiones de datos, si el interesado presta su consentimiento expresamente, podrá sustituirse la aportación de certificados en soporte papel, por el envío telemático de los datos que sean necesarios en un procedimiento administrativo. La transmisión de datos tendrá plenos efectos jurídicos en orden a la validez y eficacia de la aportación de certificados al procedimiento. 
La transmisión se realizará a petición del órgano o entidad tramitante, debiendo hacer constar los datos que se solicitan, los titulares de los mismos, y las finalidades de su utilización.

Conviene reseñar que, según estimaciones del Ministerio de Administraciones Públicas, desde su implantación se han eliminado aproximadamente seis millones de certificados que cada año los ciudadanos y empresas tenían que aportar a la Administración. Así, tanto la AEAT como la TGSS, han sustituido sus certificados por certificados telemáticos o transmisiones de datos ${ }^{42}$.

\section{Registros telemáticos}

Los registros telemáticos deberán definir y especificar en su norma de creación una serie de contenidos mínimos. Entre otros merecen destacarse: dirección o direcciones en las que se puede acceder al Registro, requisitos técnicos mínimos para acceder y usar el registro, sistemas de firma electrónica reconocidos por el registro para la identificación del usuario y la admisión de la solicitud, escrito o comunicación, procedimientos y trámites que pueden presentarse en el mismo, e indicación del calendario de días inhábiles, a efecto del cómputo de plazos ${ }^{43}$.

Respecto a sus funciones, son dos las llamadas a desarrollar:

- Recibir y remitir solicitudes escritos y comunicaciones relativas a los trámites y procedimientos autorizados y que entren dentro del ámbito competencial del órgano que creó el registro.

- Anotar los correspondientes asientos de entrada y salida.

En ningún caso servirá para compulsar o expedir copias selladas de los documentos que se transmitan con la solicitud, escrito o comunicación. 
La presentación de solicitudes, escritos y comunicaciones tendrá carácter voluntario, constituyendo una alternativa a la utilización de los registros tradicionales, teniendo además idéntico efectos jurídicos.

Su recepción se efectuara 24 horas de todos los días del año (24×365), con sujeción a las normas que rigen la fecha y hora oficial española ${ }^{44}$. Una vez presentado un documento el registro emitirá un mensaje de confirmación en el que constarán los datos aportados por el interesado, junto con la acreditación de la fecha y hora de recepción y una clave de identificación de la transmisión.

Si el usuario no recibe mensaje de confirmación, o recibe un mensaje de error o de deficiencia en la transmisión, deberá volver a realizar la presentación en otro momento o realizarlo por los medios tradicionales.

La regulación de los registros telemáticos hace de ellos un poderoso instrumento de interacción entre los usuarios y la Administración, pero no les confiere el carácter de registros generales, sino sólo limitado a los procedimientos predeterminados.

El Real Decreto 2009/2003, cumpliendo las previsiones establecidas en su disposición final primera, ha regulado por medio de la Orden PRE/ 1551/ 2003, de 10 de junio, los requisitos de autenticidad, integridad, disponibilidad y confidencialidad de los dispositivos y aplicaciones de registro y notificación, así como los protocolos y criterios técnicos a seguir.

Las medidas de seguridad, conservación y normalización son las elaboradas por el Consejo Superior de Informática y para el impulso de la Administración Electrónica ${ }^{45}$.

Por otro lado, en el ámbito de la legislación general, España también se ha incorporado a los países más avanzados en materia de regulación de las nuevas tecnologías. Así merecen destacarse, la aprobación de la Ley Orgánica 15/1999, de 13 de diciembre, de Protección de Datos de Carácter Personal ${ }^{46}$; y la reciente Ley $59 / 2003$, de 19 de diciembre, de firma electrónica ${ }^{47}$. 


\section{CONSIDERACIONES FINALES}

1. La administración electrónica o e-administración no se agota en la presencia de las administraciones públicas en Internet, ni siquiera en la prestación telemática de determinados servicios, sino que debe permitir el establecimiento de una relación directa entre los administrados y los gestores públicos, haciendo las instituciones públicas más transparentes, responsables y abiertas al control democrático.

La proliferación de los foros virtuales, consultas en línea y los ensayos de voto electrónico permiten la comunicación directa de los ciudadanos con los responsables políticos, a los que pueden hacer llegar sus opiniones, quejas, sugerencias...

2. Es necesario superar los obstáculos y barreras que dificultan la consolidación de la administración electrónica. Partiendo de perspectivas globales, debe bajarse al nivel de las necesidades concretas de los ciudadanos. Los ciudadanos deben ser el eje del diseño de las políticas de implantación de la nuevas tecnologías, optando por un sistema de acceso igualitario y facilitando las soluciones técnicas para evitar la "exclusión digital".

3. La Administración electrónica supondrá también una nueva cultura organizativa de las estructuras internas. Junto a la interoperabilidad técnica, la coordinación e integración de los diferentes organismos, constituye un elemento capital que hay que potenciar. Hay que resaltar la labor del capital humano en la implantación de las soluciones tecnologías, reconociendo e impulsando la labor que el personal administrativo está acometiendo.

4. Convienen destacar las iniciativas puestas en marcha para la implantación de la administración electrónica, tanto a nivel comunitario, como en nuestro país. Aunque inicialmente se plantearon algunas dudas, hoy caminan firmes hacia la consecución de una prestaciones y unos servicios de calidad, y son buena muestra de la decidida apuesta de los poderes públicos pro este nuevo modelo relacional. 
5. Las iniciativas desplegadas en nuestro país son una buena muestra de un ambicioso programa de cambios en la administración pública, desde una visión integradora donde todos sean partícipes y todos estén representados.

La redefinición del Consejo Superior de Informática y para el impulso de la Administración Electrónica, junto a la constitución en diciembre de 2003 de la Conferencia Sectorial de Administraciones Públicas (presidida por el Ministro de Administraciones Públicas e integrada por los Consejeros de las Comunidades Autónomas tendrá entre otras misiones la administración electrónica) son una buena muestra de ese necesario proyecto de coordinación e integración de las actuaciones en este campo.

6. Las experiencias punteras desarrolladas en España en sectores como la Administración tributaria, la seguridad social, el censo, la firma electrónica deben constituir elementos de referencia para el intercambio de buenas prácticas. Ahora bien, no se trata de copiar las experiencias, sino asumir sus claves estratégicas y adaptarlas a la definición y puesta en marcha de los nuevos servicios.

7. El marco regulatorio debe adaptarse igualmente a los nuevos apremios. Además de confianza, los ciudadanos reclaman seguridad en la utilización de las nuevas tecnologías. Las soluciones jurídicas deben ser integrales, contemplando todos los elementos afectados, y garantizando la regularidad y eficacia de los procesos. Nuestro país, se ha aupado en los últimos años al grupo de aquellos más avanzados en la regulación del fenómeno tecnológico: Protección de datos, firma electrónica, propiedad intelectual, procedimientos telemáticos, seguridad de las Redes, cibercrimen....

Pero conviene seguir avanzando y sistematizando las regulaciones. En el ámbito normativo de la administración electrónica se observa una gran concurrencia de normas, que se remiten y fundamentan unas a otras, modificaciones de las modificaciones, creando cierta confusión. Creo llegado el momento que, al menos en la legislación estatal, se proceda a elaborar una legislación unificada y concordada que agrupe la multitud de referencias existentes. 
8. Los logros conseguidos no deben hacernos conformistas o autocomplacientes. Nos encontramos ante una realidad que se produce y muta simultáneamente a nuestros esfuerzos. Las TIC no han alcanzado su horizonte último, sorprendiéndonos casi a diario con nuevos logros y nuevas potencialidades. Es por ello que no cabe hablar de proceso cerrado. La administración pública tiene mucho que decir en este cambio. Los cimientos están puestos, los empleados públicos han asumido ejemplarmente el desafío, los planes están marcha y los ciudadanos, cada vez más, utilizan y reclaman servicios electrónicos. Hemos iniciado una singladura que nos exigirá una atención constante, una predisposición a asumir nuevos desafíos, para los que hablar que encontrar novedosas soluciones.

\section{A ADMINISTRAÇÃO ELETRÔNICA NA ESPANHA}

\section{RESUMO}

A administração eletrônica supõe um novo desafio para a correta implementação da sociedade da informação e as comunicações nas relações da administração com os cidadãos. A Espanha assumiu este desafio com entusiasmo, mas assim como ocorre com a maioria dos seus sócios na comunidade européia deve fazer frente a desafios ainda maiores, como a inclusão digital, a segurança e a privacidade nas comunicações assim como a lealdade e transparência em suas atuações nos novos caminhos digitais.

Palavras-chave: Administração eletrônica. Cidadãos. Espanha. Inclusão digital.

\section{NOTAS}

1 Doctor en Derecho. Profesor de Teoría del Derecho. Universidad de Sevilla. Profesor de Política Criminal del Instituto Andaluz Interuniversitario de Criminología. Presidente de la Asoc. Andaluza de Derecho, Medio Ambiente y Desarrollo Sostenible.

2 CASTELLS, M., La Galaxia Internet: reflexiones sobre Internet, empresa y sociedad, Plaza y Janés, Madrid, 2001; y SANCHEZ BRAVO, A., Internet y la sociedad europea de la información: implicaciones para los ciudadanos, Publicaciones de la Universidad de Sevilla, 2001.

3 LIIKANEN, E., "La administración electrónica para los servicios públicos europeos del futuro", en Lección inaugural del curso académico 200-2004 de la UOC, Barcelona 2003, (en línea), OUC (24/05/04). http://www.uoc./edu/dt/20334/index.html

4 http://europa.eu.int/scadplu/leg/es/lvb/124226b.htm 
5 Ventanilla única entendida como "acceso único" a Internet para la solución de un determinado asunto. Ello implica que los ciudadanos acceden de manera simplificada y rápida, sin necesidad de conocer el departamento concreto responsable de su petición, ni las relaciones interadministrativas necesarias para satisfacerla.

6 CIS. Barometro enero 2004. http://www.cis.es/File/ViewFile.aspx?Fileld=1327

7 Vid. PÉREZ LUÑO, A.E., Derechos Humanos, Estado de Derecho y Constitución, $8^{a}$ ed. Tecnos, Madrid, 2003, especialmente su Cap. 4.

8 Sobre esta cuestión, vid. CRIADO GRANDE, J.I. y RAMILO ARAUJO, M.C., "e- administración: ¿un reto o una nueva moda?, en Revista Vasca de Administración Pública, vol. 61, n 1, pp. 11-43.

9 http://europa.eu.int/information society/eeurope/2005/all about/broadband/index en.htm\# National

10 Sobre la delimitación del derecho a la libertad informática, vid., y de entre su numerosa producción científica, PEREZ LUÑO, A.E., Nuevas Tecnologías, Sociedad y Derecho. El impacto socio-juridico de las N.T. de la información, Fundesco, Madrid, 1987; "La libertad informática. Nueva frontera de los derechos fundamentales", en la obra colectiva Libertad informática y leyes de protección de datos personales, Centro de Estudios Constitucionales, Madrid, 1989, pp. 185213; "Nuevos derechos fundamentales de la era tecnológica: la libertad informática", en Anuario de Derecho Público y Estudios Públicos, num. 2, 1989/90, pp. 171-195; "Del Habeas Corpus al Habeas Data", en Informática y Derecho, num. 1, 1992, pp. 153-161; Manual de Informática y Derecho, Ariel, Barcelona, 1996; "Aspectos jurídicos y problemas en Internet", en la obra colectiva, coord. Por J. De Lorenzo, Medios de Comunicación Social y Sociedad: De información a Control y Transformación, Consejo Social de la Universidad de Valladolid, 2000, pp. 107-134; y Derechos Humanos, Estado de Derecho y Constitución, Tecnos, $7^{\text {a }}$ edic., Madrid, 2001; y LUCAS MURILLO DE LA CUEVA, P., "La protección de los datos personales ante el uso de la informática", en Anuario de Derecho Público y Estudios Políticos, núm. 2, 1989/90, pp. 153-170; El derecho a la autodeterminación informativa. La protección de los datos personales ante el uso de la informática, Tecnos, Madrid, 1990; Informática y protección de datos personales (Estudio sobre la Ley Orgánica 5/1992, de regulación del tratamiento automatizado de los datos de carácter personal), Centro de Estudios Constitucionales, Madrid, 1993; y "La construcción del derecho a la autodeterminación informativa", en Revista de Estudios Políticos, num. 104, abril-junio 1999. Vid. asimismo, SANCHEZ BRAVO, A., La protección del derecho a la libertad informática en la Unión Europea, Publicaciones de la Universidad de Sevilla, 1998.

11 Cfr. SÁNCHEZ BRAVO, A., "Una política comunitaria de seguridad en Internet", en Diario La LEY, $\mathrm{n}^{\circ}$ 5414, 8 de noviembre de 2001, pp. 1-8.

12 Cfr. SÁNCHEZ BRAVO, A., "La protección del derecho a la libertad informática en la Unión Europea", Publicaciones de la Universidad de Sevilla, 1998, pp. 109-113.

13 SANCHEZ BRAVO, A. "El Convenio del Consejo de Europa sobre cibercrimen: control vs. libertades públicas", en Diario La Ley, núm.5528, 22 de abril de 2002.

14 De todos es sabido como a raíz de los atentados terroristas del 11 de Septiembre en EEUU se ha producido una oscilación casi universal hacia posturas que postulan una intervención de Internet, y un control sobre los usuarios y sobre la información que envían o consumen.

Así, con motivo de la aprobación en el Senado norteamericano de la nueva ley antiterrorista que limitará los poderes en la Cámara, una de las enmiendas de urgencia impulsadas tras los atentados permitiría a la fiscalía instalar en los proveedores de acceso a Internet sistemas de vigilancia de los servicios de mensajería electrónica. De hecho, unos horas después de los atentados agentes de la Oficina Federal de Investigación (FBI) se presentaros en las oficinas de los proveedores AOL, Earthlink y Hoptmail para instalar en sus servidores el programa "Carnivore", que permite interceptar las comunicaciones de sus clientes.

15 Naciones Unidas elaboró un "Manual sobre la prevención y el control de la delincuencia informática", que se ha actualizado recientemente. En 1983 la OCDE inició un estudio sobre la posibilidad de aplicar a escala internacional y armonizar los derechos penales para abordar el problema del abuso informático o de la delincuencia informática. En 1986, publico el informe "Delincuencia informática: Análisis de las medidas jurídicas", donde se examinaban las leyes y propuestas existentes para la reforma en varios Estados miembros y se recomendaba una lista mínima de abusos que los países deberían prohibir y penalizar con leyes penales. Finalmente, en 1992, la OCDE elaboró un conjunto de directrices para la seguridad de los sistemas de información, que deberían en principio proporcionar una base sobre la cual los Estados y el sector privado pudieran construir un marco para la seguridad de los sistemas de información.

$16 \mathrm{http}: / /$ conventions.coe.int/Treaty/FR/projets/FinalCybercrime.htm. La Convención fue abierta a la firma el día 23 de noviembre de 2001 en Budapest. Firmaron 26 Estados Miembros del Consejo de Europa: Albania, Alemania, Armenia, Austria, Bélgica, Bulgaria, Croacia, Chipre, España, Estonia, 
Finlandia, Francia, Grecia, Holanda, Hungría, Italia, Moldavia, Noruega, Polonia, Portugal, Reino Unido, Rumania, Suecia, Suiza, la "ex república yugoslava de Macedonia", y Ucrania. Canadá, Estados Unidos, Japón y Sudáfrica, que participaron en su elaboración, han firmado igualmente la Convención. Malta ha firmado el convenio en Estrasburgo el 17 de enero de 2002

17 Propuesta de Decisión-Marco del Consejo relativa a los ataques de los que son objeto los sistemas de información, COM(2002) 173 final. 2002/086 (CNS), Bruselas, 19.04.2002.

$18 \mathrm{http}: / / \mathrm{www}$.delitosinformaticos.com/articulos/102366322783568.shtml

19 LIIKANEN, E., "La administración electrónica para los servicios públicos europeos del futuro", cit., p. 19.

20 BUENO GARCÍA, O., "Modernización de la Administración Pública: Líneas estratégicas para la eadministración", en http://www.lawebmunicipal.com/publicaciones/onalia/onalia.htm

21 http://www.telefonica.es/sociedaddelainformacion/espana2003/

22 Ibid.

${ }^{23}$ Sobre los distintos modelos de articulación de la cooperación administrativa, vid., Análisis y propuestas para la modernización de la administración pública, Asociación Profesional del Cuerpo Superior de Sistemas y Tecnologías de la Información de la Administración del Estado, en http://www.astic.es/nr/astic/Boletic-todos/Boletic29/separata/astic-AP-AE.pdf

24 http://www.aeat.es/

25 http://www.seg-social.es/inicio/

${ }^{26} \mathrm{http}: / / \mathrm{www}$.ine.es/censoe/menucenso.htm

27 http://www.cert.fnmt.es

28 BARROSO BARRERO, J., "La Administración Electrónica en España: un análisis de los sectores claves", en El Comercio en la SI. Información Comercial Española. Revista de Economía, febrero 2004, no 813, pp. 55-71. http://www.mcx.es/polcomer/estudios/Documen/ice/813/ICE8130107.PDF

29 Andalucía. Segunda Modernización. Estrategias y Propuestas, Consejería de la Presidencia de la Junta de Andalucía, Sevilla, 2003, p. 87.

30 BOE de 27 de noviembre de 1992.

\section{Artículo 45. Incorporación de medios técnicos.}

1. Las Administraciones Públicas impulsarán el empleo y aplicación de las técnicas y medios electrónicos, informáticos y telemáticos, para el desarrollo de su actividad y el ejercicio de sus competencias, con las limitaciones que a la utilización de estos medios establecen la Constitución y las Leyes.

2. Cuando sea compatible con los medios técnicos de que dispongan las Administraciones Públicas, los ciudadanos podrán relacionarse con ellas para ejercer sus derechos a través de técnicas y medios electrónicos, informáticos o telemáticos con respecto de las garantías y requisitos previstos en cada procedimiento.

3. Los procedimientos que se tramiten y terminen en soporte informático garantizarán la identificación y el ejercicio de la competencia por el órgano que la ejerce.

4. Los programas y aplicaciones electrónicos, informáticos y telemáticos que vayan a ser utilizados por las Administraciones Públicas para el ejercicio de sus potestades, habrán de ser previamente aprobados por el órgano competente, quien deberá difundir públicamente sus características.

5. Los documentos emitidos, cualquiera que sea su soporte, por medios electrónicos, informáticos o telemáticos por las Administraciones Públicas, o los que éstas emitan como copias de originales almacenados por estos mismos medios, gozarán de la validez y eficacia de documento original siempre que quede garantizada su autenticidad, integridad y conservación y, en su caso, la recepción por el interesado, así como el cumplimiento de las garantías y requisitos exigidos por ésta u otras Leyes.

31 BOE de 31 de diciembre de 2001.

32 Artículo 68. Modificaciones de la Ley 30/1992, de Régimen Jurídico de las Administraciones Públicas y del Procedimiento Administrativo Común para impulsar la administración electrónica.

Uno. Se añade un nuevo apartado nueve al artículo 38 de la Ley 30/1992, de Régimen Jurídico de las Administraciones Públicas y del Procedimiento Administrativo Común, con la siguiente redacción:

"Se podrán crear registros telemáticos para la recepción o salida de solicitudes, escritos y comunicaciones que se transmitan por medios telemáticos, con sujeción a los requisitos establecidos en el apartado 3 de este artículo. Los registros telemáticos sólo estarán habilitados para la recepción o salida de las solicitudes, escritos y comunicaciones relativas a los procedimientos y trámites de la competencia del órgano o entidad que creó el registro y que se especifiquen en la norma de creación de éste, así como que cumplan con los criterios de 
disponibilidad, autenticidad, integridad, confidencialidad y conservación de la información que igualmente se señalen en la citada norma.

Los registros telemáticos permitirán la presentación de solicitudes, escritos y comunicaciones todos los días del año durante las veinticuatro horas. A efectos de cómputo de plazos, la recepción en un día inhábil para el órgano o entidad se entenderá efectuada en el primer día hábil siguiente."

33 Dos. Se añade un nuevo apartado 3 al artículo 59 de la Ley 30/1992, de Régimen Jurídico de las Administraciones Públicas y del Procedimiento Administrativo Común, con la redacción que a continuación se seña la, pasando los actuales apartados 3,4 y 5 del citado artículo a numerarse como 4,5 y 6 .

"Para que la notificación se practique utilizando medios telemáticos se requerirá que el interesado haya seña lado dicho medio como preferente o consentido expresamente su utilización, identificando además la dirección electrónica correspondiente, que deberá cumplir con los requisitos reglamentariamente establecidos. En estos casos, la notificación se entenderá practicada a todos los efectos legales en el momento en que se produzca el acceso a su contenido en la dirección electrónica. Cuan

do, existiendo constancia de la recepción de la notificación en la dirección electrónica, transcurrieran diez días naturales sin que se acceda a su contenido, se entenderá que la notificación ha sido rechazada con los efectos previstos en el siguiente apartado, salvo que de oficio o a instancia del destinatario se compruebe la imposibilidad técnica o material del acceso."

34 Artículo 2. Derechos de los ciudadanos y limitaciones.

1. La utilización de las técnicas señaladas en el artículo anterior tendrá las limitaciones establecidas por la Constitución, la Ley 30/1992, de Régimen Jurídico de las Administraciones Públicas y del Procedimiento Administrativo Común, y el resto del ordenamiento jurídico, respetando el pleno ejercicio por los ciudadanos de los derechos que tienen reconocidos. En especial, se garantizará el honor y la intimidad personal y familiar de los ciudadanos ajustándose, a tal efecto, a lo dispuesto en la Ley Orgánica 5/1992, de Regulación del tratamiento automatizado de los datos de carácter personal, y en las demás Leyes específicas que regulan el tratamiento de la información así como en sus correspondientes normas de desarrollo.La utilización de tales técnicas en ningún caso podrá implicar la existencia de restricciones o discriminaciones de cualquier naturaleza en el acceso de los ciudadanos a la prestación de servicios públicos o a cualquier actuación o procedimiento administrativo.

2. Cuando la Administración General del Estado o las entidades de derecho público vinculadas o dependientes de aquélla utilicen técnicas electrónicas, informáticas y telemáticas en actuaciones o procedimientos que afecten de forma directa o indirecta a derechos o intereses de los ciudadanos, se garantizará la identificación y el ejercicio de la competencia por el órgano correspondiente. En este supuesto, los ciudadanos tendrán derecho a obtener información que permita la identificación de los medios y aplicaciones utilizadas, así como del órgano que ejerce la competencia.

35 BOE de 22 de mayo de 1999.

36 BOE de 28 de febrero de 2003.

37 Mediante la Dirección Electrónica Única (DEU) cualquier persona física o jurídica que lo solicite dispondrá de una dirección electrónica, que será única para la recepción de las notificaciones administrativas que por vía telemática pueda practicar la Administración General del Estado y sus Organismos Públicos. Su solicitud es voluntaria y tiene carácter gratuito.

Asociado a la Dirección Electrónica Única, su titular dispondrá de un buzón electrónico en el que recibirá las notificaciones telemáticas correspondientes a aquellos procedimientos a los que voluntariamente decida suscribirse. Este servicio cumple con las máximas garantías de confidencialidad, autenticidad y privacidad con el fin de asegurar la identidad de los participantes y de las comunicaciones.

Para utilizar este servicio, el interesado deberá disponer de un certificado digital estándar X.509 emitido a su nombre o de la empresa que representa como por ejemplo, el clase 2CA emitido por la Fábrica Nacional de Moneda y Timbre, y completar el formulario existente en la opción de menú "Crear una DEU". http://notificaciones.administracion.es/portalciudadano/DE que es.asp

38 Revocación por el titular, fallecimiento de la persona física o extinción de la personalidad jurídica o resolución judicial o administrativa que así lo ordene.

39 Los ciudadanos que dispongan de una Dirección Electrónica Única, podrán suscribirse a los procedimientos que la Administración General del Estado y sus organismos públicos habiliten para la recepción de las notificaciones por vía telemática. Estos procedimientos podrán ser iniciados de oficio por la Administración o por el propio interesado, indicando su preferencia acerca del modo en que desea ser notificado. http://notificaciones.administracion.es/portalciudadano/faqs.asp

40 Una notificación puede encontrarse en los siguientes estados: 
- Puesta a Disposición, cuando el destinatario ha recibido la notificación en su buzón y está disponible para su aceptación y lectura, o rechazo.

- Leído, si el destinatario ha accedido a la notificación y ha procedido a descifrado y lectura correctamente.

- $\quad$ Rechazado, si el usuario ha decidido no leer esa notificación de forma expresa.

- Rechazado de forma automática, si ha transcurrido el plazo de 10 días que establece la ley de validez de las notificaciones administrativas sin que el ciudadano haya leído o rechazado la notificación.

El estado de una notificación es comunicado en forma de copia telemática de la siguiente información:

- Acuses de puesta a disposición (fecha electrónica en la que la notificación estuvo disponible en el buzón y firma del emisor de la notificación).

- Acuses de recibo (fecha electrónica y firma en la que la notificación fue leída o rechazada por el destinatario).

http://notificaciones.administracion.es/portalciudadano/fags.asp

41 BARROSO BARRERO, J., "La Administración Electrónica en España...”, cit., p. 69.

42 Ibid.

43 Real Decreto 209/2003. Artículo 18. Cómputos.

La presentación de solicitudes, escritos y comunicaciones en los registros telemáticos, su recepción, así como las remisiones de escritos y comunicaciones por aquellos, se regirá a los efectos de cómputo de los plazos fijados en días hábiles por los siguientes criterios:

a) Serán considerados días inhábiles para los registros telemáticos y para los usuarios de estos sólo los así declarados para todo el territorio nacional en el calendario anual de días inhábiles. Para aquellos registros telemáticos destinados a la recepción de solicitudes, escritos y comunicaciones referentes a trámites o procedimientos cuya instrucción y resolución corresponda a órganos cuya competencia esté territorialmente delimitada a una Comunidad Autónoma, provincia o municipio, serán también inhábiles los así declarados en el ámbito territorial correspondiente.

b) La entrada de las solicitudes, escritos y comunicaciones recibidas en un día inhábil para el registro telemático se entenderá efectuada en la primera hora del primer día hábil siguiente. $\mathrm{A}$ estos efectos, en el asiento de la entrada se inscribirán como fecha y hora de presentación aquellas en las que se produjo efectivamente la recepción; constando como fecha y hora de entrada las cero horas y un segundo del primer día hábil siguiente.

c)Los registros telemáticos no realizarán ni anotarán salidas de escritos y comunicaciones en días inhábiles."

44 Artículo 17. Recepción.

1. La presentación de solicitudes, escritos y comunicaciones podrá realizarse en los registros telemáticos durante las 24 horas de todos los días del año. Los registros telemáticos se regirán por la fecha y hora oficial española, que deberá figurar visible en la dirección electrónica de acceso al registro. La hora oficial, a efectos del registro telemático, será la correspondiente a la península y el archipiélago balear, salvo que el registro tenga como ámbito territorial la Comunidad Autónoma de Canarias, en cuyo caso será la hora oficial correspondiente al archipiélago canario. http://www.csi.map.es/csi/pg5c10.htm

46 BOE de 14 de diciembre de 1999. Vid. a este respecto, APARICIO SALOM, J., Estudio sobre la Ley Orgánica de protección de datos de carácter personal, 2. ${ }^{a}$ edición, Pamplona, Aranzadi, 2002; DEL PESO NAVARRO, E., "Ley de Protección de Datos. La nueva LORTAD", Editorial Díaz de Santos, Madrid 2000; FREIXAS GUTIERREZ, G. "La protección de datos de carácter personal en el derecho español", Editorial Bosch, Barcelona 2001; GARRIGA DOMÍNGUEZ, A., Tratamiento de Datos Personales y Derechos Fundamentales, Dykinson, Madrid, 2004; PEREZ LUÑO, A.E., "Sobre el Arte Legislativo de Birlibirloque. la LOPRODA y la Tutela de la Libertad Informática en España", Anuario de Filosofía del Derecho. 2002. Pag. 321-361; SÁNCHEZ BRAVO, A., "La Ley Orgánica 15/1999 de protección de datos de carácter personal: diez consideraciones en torno a su contenido", Revista de Estudios políticos, n 111, 2001, pp. 201-214; TÉLLEZ AGUILERA, A., "Nuevas Tecnologías. Intimidad y protección de datos", Editorial Edisofer, Madrid 2001; ULL PONT, E. "Derecho Público de la informática", Ediciones UNED, Madrid 2000; VIZCAíNO CALDERON, M., "Comentarios a la ley orgánica de protección de datos de carácter personal", Editorial Cívitas, Madrid 2001.

47 BOE de 20 de diciembre de 2003. Vid. a este respecto, DE QUINTO ZUMARRAGA, F., La firma electrónica: marco legal y aplicaciones prácticas, Difusión Jurídica y Temas de Actualidad, S.A., Madrid, 2004. 


\section{REFERÊNCIAS}

ANDALUCÍA. Segunda Modernización. Estrategias y Propuestas, Consejería de la Presidencia de la Junta de Andalucía, Sevilla, 2003.

APARICIO SALOM, J., Estudio sobre la Ley Orgánica de protección de datos de

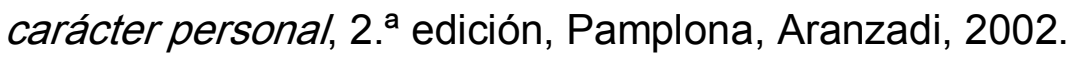

BARROSO BARRERO, J., "La Administración Electrónica en España: un análisis de Ios sectores claves", en El Comercio en la SI. Información Comercial Española. Revista de Economía, febrero 2004, nº 813.

BOE de 14 de diciembre de 1999.

BOE de 20 de diciembre de 2003.

BOE de 22 de mayo de 1999.

BOE de 27 de noviembre de 1992.

BOE de 28 de febrero de 2003.

CASTELLS, M., La Galaxia Internet: reflexiones sobre Internet, empresa y sociedad, Plaza y Janés, Madrid, 2001.

CIS. Barometro enero 2004.

CRIADO GRANDE, J.I. y RAMILO ARAUJO, M.C., "e- administración: ¿un reto o una nueva moda?, en Revista Vasca de Administración Pública, vol. 61, nº 1.

DE QUINTO ZUMARRAGA, F., La firma electrónica: marco legal y aplicaciones prácticas, Difusión Jurídica y Temas de Actualidad, S.A., Madrid, 2004.

DEL PESO NAVARRO, E., "Ley de Protección de Datos. La nueva LORTAD", Editorial Díaz de Santos, Madrid 2000;

FREIXAS GUTIERREZ, G. "La protección de datos de carácter personal en el derecho español", Editorial Bosch, Barcelona 2001;

GARRIGA DOMínGUEZ, A., Tratamiento de Datos Personales y Derechos Fundamentales, Dykinson, Madrid, 2004; 
LIIKANEN, E., "La administración electrónica para los servicios públicos europeos del futuro", en Lección inaugural del curso académico 200-2004 de la UOC, Barcelona 2003, (en línea), OUC (24/05/04).

LUCAS MURILLO DE LA CUEVA, P., "La protección de los datos personales ante el uso de la informática", en Anuario de Derecho Público y Estudios Políticos, núm. 2, 1989/90.

PEREZ LUÑO, A.E., “Aspectos jurídicos y problemas en Internet”, en la obra colectiva, coord. Por J. De Lorenzo, Medios de Comunicación Social y Sociedad: De información a Control y Transformación, Consejo Social de la Universidad de Valladolid, 2000.

PEREZ LUÑO, A.E., “ Del Habeas Corpus al Habeas Data”, en Informática y Derecho, num. 1, 1992.

PEREZ LUÑO, A.E., "La libertad informática. Nueva frontera de los derechos fundamentales", en la obra colectiva Libertad informática y leyes de protección de datos personales, Centro de Estudios Constitucionales, Madrid, 1989.

PEREZ LUÑO, A.E., "Nuevos derechos fundamentales de la era tecnológica: la libertad informática", en Anuario de Derecho Público y Estudios Públicos, num. 2, 1989/90.

PEREZ LUÑO, A.E., "Sobre el Arte Legislativo de Birlibirloque. la LOPRODA y la Tutela de la Libertad Informática en España”, Anuario de Filosofía del Derecho. 2002.

PEREZ LUÑO, A.E., Derechos Humanos, Estado de Derecho y Constitución, Tecnos, $7^{\mathrm{a}}$ edic., Madrid, 2001;

PÉREZ LUÑO, A.E., Derechos Humanos, Estado de Derecho y Constitución, $8^{a}$ edic., Tecnos, Madrid, 2003.

PEREZ LUÑO, A.E., Manual de Informática y Derecho, Ariel, Barcelona, 1996; PEREZ LUÑO, A.E., Nuevas Tecnologías, Sociedad y Derecho. El impacto sociojuridico de las N.T. de la información, Fundesco, Madrid, 1987;

Real Decreto 209/2003. 
SANCHEZ BRAVO, A. "El Convenio del Consejo de Europa sobre cibercrimen: control vs. libertades públicas", en Diario La Ley, núm.5528, 22 de abril de 2002. SÁNCHEZ BRAVO, A., "La Ley Orgánica 15/1999 de protección de datos de carácter personal: diez consideraciones en torno a su contenido", Revista de Estudios políticos, $\mathrm{n}^{\circ}$ 111, 2001.

SÁNCHEZ BRAVO, A., "La protección del derecho a la libertad informática en la Unión Europea", Publicaciones de la Universidad de Sevilla, 1998.

SÁNCHEZ BRAVO, A., "Una política comunitaria de seguridad en Internet", en Diario La LEY, n 5414, 8 de noviembre de 2001.

SANCHEZ BRAVO, A., Internet y la sociedad europea de la información:

implicaciones para los ciudadanos, Publicaciones de la Universidad de Sevilla, 2001.

SANCHEZ BRAVO, A., La protección del derecho a la libertad informática en la Unión Europea, Publicaciones de la Universidad de Sevilla, 1998.

TÉLLEZ AGUILERA, A., "Nuevas Tecnologías. Intimidad y protección de datos", Editorial Edisofer, Madrid 2001;

ULL PONT, E. "Derecho Público de la informática", Ediciones UNED, Madrid 2000; VIZCAÍNO CALDERON, M., "Comentarios a la ley orgánica de protección de datos de carácter personal", Editorial Cívitas, Madrid 2001.

\section{Sitios}

http://europa.eu.int/information_society/eeurope/2005/all_about/broadband/index_en. htm\#National

http://europa.eu.int/scadplu/leg/es/lvb/124226b.htm

http://notificaciones.administracion.es/portalciudadano/DE_que_es.asp

http://notificaciones.administracion.es/portalciudadano/faqs.asp

http://www.aeat.es/

http://www.cert.fnmt.es

http://www.cis.es/File/ViewFile.aspx?Fileld=1327

http://www.delitosinformaticos.com/articulos/102366322783568.shtml 
http://www.ine.es/censoe/menucenso.htm

http://www.lawebmunicipal.com/publicaciones/onalia/onalia.htm http://www.mcx.es/polcomer/estudios/Documen/ice/813/ICE8130107.PDF http://www.seg-social.es/inicio/

http://www.telefonica.es/sociedaddelainformacion/espana2003/

http://www.uoc./edu/dt/20334/index.html

Recebido para publicação 06/11/2007

Aceito para publicação26/11/2007 